Arch Bronconeumol. 2012 September ; 48(9): . doi:10.1016/j.arbres.2012.04.011.

\title{
Role of MicroRNAs in Lung Disease
}

\author{
Martín Angulo ${ }^{a, b}$, Emilia Lecuona $^{a}$, and Jacob lasha Sznajder ${ }^{a,}$ \\ ${ }^{a}$ Division of Pulmonary and Critical Care, Feinberg School of Medicine, Northwestern University, \\ Chicago, IL, USA \\ bDepartamento de Fisiopatología, Hospital de Clínicas, Facultad de Medicina, Universidad de la \\ República, Montevideo, Uruguay
}

\begin{abstract}
MicroRNAs (miRNAs) are small non-coding RNA molecules that negatively regulate gene expression. They actively participate in the modulation of important cell physiological processes and are involved in the pathogenesis of lung diseases such as lung cancer, pulmonary fibrosis, asthma and chronic obstructive pulmonary disease. A better understanding of the role that miRNAs play in these diseases could lead to the development of new diagnostic and therapeutic tools. In this review, we discuss the role of some miRNAs in different lung diseases as well as the possible future of these discoveries in clinical applications.
\end{abstract}

\section{Keywords}

MicroRNA; Lung disease; Smoking; Chronic obstructive pulmonary disease; Lung cancer;

Pulmonary fibrosis; Lung injury; Asthma

\section{Introduction}

In recent decades, proteomic and genomic analyses have enabled us to better understand the pathogenesis of certain lung diseases. Nevertheless, as the knowledge of their physiopathology advances, the complexity of the system and the number of "actors" involved seem to increase. After exposure to a noxa, different cell processes and mediators intervene before the disease becomes evident. In this respect, microRNAs (miRNAs) seem to play an important role in the development and progression of pulmonary pathologies. ${ }^{1-6}$

MiRNAs are a type of non-coding, evolutionally preserved, small-sized RNA that are able to regulate genic expression by different mechanisms. ${ }^{7}$ Even though several years passed between the discovery of the first miR (lin-4) in 1993 and the characterization of the second member of the family, to date the number of miRNAs described and the quantity of scientific publications about them have grown exponentially. ${ }^{8}$ Close to 2000 human miRNAs have been described (Sanger miRBase version 18) that are involved in the control of important physiological processes and in the pathogenesis of different diseases. $5,7,9$

\footnotetext{
Please cite this article as: Angulo M, et al. Rol de los microARN en las enfermedades pulmonares. Arch Bronconeumol. 2012;48:325-30.

() 2012 SEPAR. Published by Elsevier España, S.L. All rights reserved.

"Corresponding author. j-sznajder@northwestern.edu (J.I. Sznajder). .

Conflict of Interest

The authors declare having no conflict of interests.
} 


\section{Biogenesis and MicroRNA Function}

MiRNAs can be located in the introns or exons of proteincoding genes or in non-coding sectors of the genome. Once activated, the transcription is carried out by RNA polymerase II or III, originating an RNA structure in the shape of a hairpin that constitutes the primary transcript of the miR (pri-miR, Fig. 1). ${ }^{7}$ Within the nucleus, both ends of the pri-miR are cut by the Drosha/DGCR8 complex, giving rise to the precursor of mature miR (pre-miR), with an approximate size of 70-100 nucleotides. This is actively transported to the cytoplasm through Exportin-5, where it is processed by the Dicer/TRBP complex, originating a doublechain RNA molecule that is 19-25 nucleotides long. One of the chains constitutes the mature $\mathrm{miR}$, while its complement (called $\mathrm{miR}^{*}$ ) is generally degraded. Mature miR is incorporated into the RNA-induced silencing complex (RISC), whose most important complexes are the proteins of the Argonaut family. ${ }^{10}$

MiRNAs are fundamentally repressors of genic expression at the posttranscriptional level, degrading messenger RNA (mRNA) or inhibiting its protein translation. ${ }^{11}$ Once miR is incorporated into the RISC (miRISC), the complex is able to recognize the target mRNA by means of the interaction between complementary regions of the miR and mRNA. Although there are exceptions, as a general rule the binding site is at the $3^{\prime}$ end of the non-coding region of the mRNA. The degree of complementarity between both seems to be one of the determinants of the repression mechanism that is started: degradation of the mRNA if it is almost perfect or inhibition of the translation when the complementarity is lower. Although it was thought that the degradation of mRNA was an uncommon mechanism in animal cells, it has been currently demonstrated to have an important role. ${ }^{12}$ It is relevant that certain mRNA can be the target of a large number of miRNAs, in the same way that each miR can repress tens or hundreds of genes. In addition, there is evidence that suggests the possible transference of miRNAs from one cell to another, generating an interesting mechanism of intercellular regulation and communication. ${ }^{13-15}$

The activity of miRNAs is strictly regulated by means of the control of their transcription, of the different stages of biogenesis and later of the function of the miRISC. ${ }^{16,17}$ Recently, a complex communication network has been described between long non-coding RNA molecules (product of the transcription of pseudogenes), miR and mRNA. ${ }^{18,19}$ These molecules of non-coding RNA (from hundreds to thousands of nucleotides) have binding sites for specific miRNAs, and they behave like true "catchers" of miRNAs, impeding them to repress the target mRNA.

Taking into account the enormous capacity of the miRNAs to influence the expression of a large part of the genome and the intricate control system in which they are immersed, it is comprehensible that their deregulation has significant repercussions on the homeostasis of the organism. A growing number of miRNAs have been shown to be involved in different lung diseases, enabling us to better understand their pathogenesis.

\section{Smoking}

Smoking is the main risk factor for the development of chronic obstructive pulmonary disease (COPD) and lung cancer and it is estimated to be responsible for almost 5 million deaths per year. ${ }^{20}$ It has been demonstrated that tobacco smoke causes changes in the gene expression of the respiratory epithelium, which is linked to the development of these diseases. ${ }^{21}$ Alterations in the levels of certain miRNAs seem to be involved in this process (Table 1). Thus, significant changes have been found in the lung expression of 133 miRNAs in rats exposed to cigarette smoke, some of which may participate in the carcinogenic process. ${ }^{22}$ Specifically, they would favor cell proliferation and angiogenesis, while at the same time reducing the activity of tumor suppressor mechanisms. Among the miRNAs 
whose expression is more diminished are miR-34c and several members of the let-7 family, which, as we will see further ahead, have been linked with the pathogenesis of lung cancer. Together with let-7, the reduction in the levels of miR-10a, miR-123, miR-145 and miR-222 promotes angiogenesis, which is fundamental for tumor development and growth. Schembri et al. compared the profile of miRNAs in the bronchial epithelium between smokers and non-smokers, finding significant differences in the expression of 28 miRNAs. ${ }^{23}$ Reduced levels of miR-199b and miR-218 have been found in smokers, as observed in lung cancer patients. $^{24,25}$ Van Pottelberge et al. reported differences in the expression of 34 miRNAs between the induced sputum of smokers and non-smokers. ${ }^{26}$ Among them, the reduction of miR-150 could be relevant in the deteriorated the lung function linked with smoking, since certain genes involved are targets for this miR. Members of the let-7 family, miR-34c, miR-218 and miR-222 are some of the miRNAs that were found to be lower in at least two studies, underlining the importance that they could have in the pathogenesis of diseases related with smoking, such as COPD or lung cancer. ${ }^{22,23,26}$

\section{Chronic Obstructive Pulmonary Disease}

COPD constitutes the fourth cause of death in the world, and it is estimated to become the third by the year $2020 .{ }^{27}$ Despite the fact that much has been learned about the pathogenesis of this disease with systemic inflammatory components, few studies until now have focused on the role of miRNAs in COPD (Table 1). Sato et al. reported that the pulmonary fibroblasts of COPD patients present less expression of miR-146a after stimulation with proinflammatory cytokines when compared with non-COPD subjects that had similar smoking histories. ${ }^{28}$ This causes an overexpression of cyclooxygenase-2 (target of miR-146a) and a subsequent increase in the production of prostaglandin E2 (PGE2). Interestingly, the production of PGE2 and the expression of post-stimulation miR-146a are associated with the severity of the disease examined by forced expiratory volume in one second $\left(\mathrm{FEV}_{1}\right){ }^{28}$

The analysis of miRNA profiles in the induced sputum of COPD patients shows differences with that of non-smokers or smokers without airflow obstruction. ${ }^{26}$ In particular, the expression of let-7c and miR-146a is less in individuals with COPD who continue to smoke than in smokers without airway obstruction. The tumor necrosis factor receptor 2 (TNFR2) involved in the pathogenesis of COPD is one of the target mRNAs of let-7c. In these patients, the lower expression of let- $7 \mathrm{c}$ in sputum correlates inversely with the concentration of TNFR2. There is also a correlation between the level of let-7c and $\mathrm{FEV}_{1}$. In this way, the reduction of miR-146a and let-7c could be two of the determinants of the inflammatory state and the progression of COPD. Furthermore, taking into account that the reduction in the levels of let-7 is linked with carcinogenesis, the question arises as to whether alterations in the expression of certain miRNAs can contribute to the increased risk for lung cancer in COPD patients. ${ }^{26,29}$

Recently, Ezzie et al. studied miRNA levels in the lung tissue of smokers with and without COPD. ${ }^{30}$ Seventy miRNAs presented different degrees of expression between the two groups. Some of these alterations, like the increase in members of the miR-15/107 family could affect important signaling pathways in the pathogenesis of COPD, such as transforming growth factor $\beta$ (TGF- $\beta$ ) or the proteins from the Wnt family.

Peripheral muscle dysfunction is a frequent manifestation in COPD that is associated with poorer quality of life and higher mortality. ${ }^{31,32}$ Atrophy and the change in the type of muscle fiber (reduction in the percentage of slow-contracting fibers and increase in fastcontracting fibers) constitute a characteristic phenotype. ${ }^{33}$ Lewis et al. found a reduction of 2.5 times in the expression of miR-1 in the quadriceps of patients with COPD, compared with healthy individuals. ${ }^{34}$ The authors have also demonstrated a positive correlation 
between the levels of miR-1 and functional and severity indices of the disease, such as $\mathrm{FEV}_{1}$, the 6-min walk test and the St. George's respiratory questionnaire, as well as with the percentage of slow muscle fibers (type I). At the same time, the patients presented greater levels of histone deacetylase 4 protein (whose mRNA is a target of miR-1) at the muscular level, which could explain a connection between the decrease in miR-1 and the change in fiber type. ${ }^{34}$ Other relevant miRNAs in muscle biology, such as miR-206, miR-208 or miR-499, did not present significant differences between COPD patients and healthy individuals. ${ }^{34}$

\section{Lung Cancer}

Lung cancer represents an important cause of mortality worldwide. ${ }^{35}$ Despite the advances in diagnostic and therapeutic techniques, the 5 -year survival rate continues to be very low. ${ }^{36}$ MiRNAs actively participate in the regulation of cell processes like proliferation, differentiation and apoptosis. It is therefore not surprising to see the evidence about abnormalities in the expression of miRNAs in different types of cancer, acting in certain cases as oncogenes (called oncomiRNAs) while in others as tumor suppressors. Lung cancer, especially non-small-cell (NSCLC), is the respiratory pathology in which miRNAs have been more extensively studied (Table 1). There is great interest in their possible usefulness for the early detection of the disease, subclassification of the different types of cancer, prognostic staging, identification of patients with a greater probability of resistance to chemotherapy and eventual therapeutic tool. ${ }^{37,38}$

The reduction in the levels of the Dicer enzymes, necessary for the maturation of the miRNAs, has been reported in the tumor tissue of patients with lung cancer in whom it had a prognostic impact on survival. ${ }^{39}$ The members of the miR-17-92 group, overexpressed in small-cell lung cancer, favor tumor development and neovascularization. ${ }^{37,40}$ Liu et al. also demonstrated the role of miR-31 as oncomiR in NSCLC, where it represses tumor suppressor genes. ${ }^{41}$ Meanwhile, miR-21 presents higher levels in lung cancer both in nonsmokers as well as smoker patients. ${ }^{42}$ This miR promotes cell growth and inhibits apoptosis, favoring tumor growth and the development of metastasis. ${ }^{38}$ The members of the miRNA let-7 are characterized as tumor suppressor genes, repressing oncogenes like ras, myc and HMGA2. ${ }^{37}$ The expression of let-7 is frequently seen to be lower in lung cancer, having a negative impact on the survival of patients who are treated surgically. ${ }^{43}$ The transcription of miR-34 is directly induced by tumor suppressor p53 in response to DNA damage, inhibiting inappropriate cell proliferation. ${ }^{44}$ The expression of this miR is reduced in the tumor tissue, associated with a greater risk of relapse after surgical resection. ${ }^{45,46}$ There is also a reported decrease in the levels of miR-1 and miR-133b in the tumor tissue. ${ }^{47,48}$ This is associated with an increase in some of target compositions (MET, Pim-1, HDAC4, MCL-1, BCL2L2) involved in pulmonary carcinogenesis. ${ }^{47,48}$ The lower expression of miR-218 in the tumors of patients with NSCLC has also led it to be proposed as a possible miR tumor suppressor. ${ }^{24}$

The study of miRNAs can become an important diagnostic tool in the short to mid-term. The histologic classification of lung cancer may be incomplete, especially in cases of tumors that are not very differentiated, or when the biopsy material is limited. The presence of mutations and expression of certain biomarkers suggest the possible existence of a greater number of subcategories with different prognoses. Therefore, the detection of certain miRNAs may be useful to understand and identify the different types of cancer. ${ }^{37}$ Moreover, beyond the analysis at the tumor tissue level, miRNAs can be detected in samples obtained in a minimally invasive manner. ${ }^{49}$ Reports have started describing miRNA expression patterns in serum and sputum that could facilitate the early detection of patients with lung cancer. $^{50-52}$ In the same way, the finding of certain miRNAs in tumor tissue has prognostic implications. Yanaihara et al. reported that the high expression of miR-155 and the low 
expression of let-7a-2 correlate with poorer survival in patients with lung adenocarcinoma. ${ }^{25}$ $\mathrm{Yu}$ et al. described how the expression profile of 5 miRNAs was associated with the prognosis in patients with NSCLC, with let-7a and miR-221 acting as protectors, while miR-137, miR-372 and miR-182* increase the risk of death. ${ }^{53}$ In patients with squamous cell carcinoma, the higher miR-146b in tumor tissue is associated with shorter survival. ${ }^{54}$ At the serum level, the detection of high levels of miR-486 and miR-30d together with low levels of miR-1 and miR-499 has also been associated with a worse prognosis. 55

Finally, there is much expectation about the role that miRNAs may have in the development of therapeutic strategies in lung cancer. Resistance to chemo and radiotherapy is currently one of the main problems for treatment. The expression of some miRNAs has been implicated in the therapeutic resistance mechanisms in lung cancer. ${ }^{49}$ This discovery opens up the possibility not only of guiding treatment based on the profile of miRNAs, but also their eventual modulation for increasing the tumor sensitivity to chemotherapy. The field of miRNA manipulation in vivo is still being developed. Nevertheless, both the inhibition of specific oncomiRNAs as well as the restored expression of miRNAs tumor suppressors could represent an important advancement in lung cancer treatment.

\section{Idiopathic Pulmonary Fibrosis}

Idiopathic pulmonary fibrosis (IPF) is a chronic disease characterized by pulmonary interstitial fibrosis and progressive lung function deterioration. Its cause is unknown, and the therapeutic possibilities are limited. ${ }^{56}$ The fibrosis and distortion of the lung parenchyma may be a product of the activation of the alveolar epithelial cells, stimulating an epithelialmesenchymal transition (EMT) with an accumulation of fibroblasts and myofibroblasts that express extracellular matrix. ${ }^{57}$ Despite there being few published studies, the role of miRNAs in the pathogenesis of IPF is beginning to gain relevance (Table 1). Pandit et al. reported significant differences in the expression of 46 miRNAs between the lungs of patients with IPF and control subjects. ${ }^{58}$ Among healthy individuals, there is a decrease in let-7d, whose levels in the alveolar epithelium correlate with forced vital capacity. The TGF$\beta$ cytokine represses the transcription of let-7d, determining an increase in HMGA2, one of the targets of miR. Both TGF- $\beta$ as well as HMGA2 have been involved in the development of EMT in pulmonary fibrosis. ${ }^{59}$ The repression of let-7d also could generate the overexpression of other compositions linked with the fibrotic process, like the growth factor similar to insulin 1 and its receptor. ${ }^{58}$

MiR-21 levels are higher in the lungs of patients with IPF, and this increase is mainly located in the fibroblasts/myofibroblasts. ${ }^{60}$ The expression of miR-21 is induced by TGF- $\beta$; meanwhile, miR-21 represses Smad7, promoting the activation of fibroblasts mediated by TGF- $\beta$. In this way, miR-21 participates in a circuit of positive feedback with TGF- $\beta$, favoring the fibrotic process. Yang et al. recently reported that the expression of miR-200 is lower in the lungs of patients with IPF (miR-200a, miR-200c) and in an animal model of pulmonary fibrosis (miR-200a, miR-200b, miR-200c). ${ }^{61}$ The authors demonstrated that miR-200 inhibits EMT induced by TGF- $\beta$ in alveolar epithelial cells, possibly by means of the repression of certain transcription factors involved in the process, like GATA3, ZEB1 or ZEB2. However, TGF- $\beta$ itself negatively regulates the expression of miR-200. Interestingly, both the treatment with miR-200 and the inhibition of miR-21 reduce experimental pulmonary fibrosis in rats. ${ }^{60,61}$

The pulmonary expression of miR-29 is lower in mice after the induction of pulmonary fibrosis, modifying the expression of several genes associated with the extracellular matrix. ${ }^{62}$ In patients with IPF, the lung levels of miR-29 are also seen to be lower. ${ }^{58,63}$ The inhibition of miR-29 seems to be mediated once again by TGF- $\beta .^{62}$ Lastly, miR-155 was found to be high in the lungs of patients with IPF and animals with experimental 
fibrosis. ${ }^{58,64}$ This miR represses the keratinocyte growth factor in fibroblasts and increases their migration. ${ }^{64}$

\section{Pulmonary Lesion}

Acute pulmonary lesion (APL) and acute respiratory distress syndrome (ARDS) are characterized by lesion and lung inflammation, determining edema, reduced distensibility and compromised gas exchange. ${ }^{65}$ Alterations in the expression of certain miRNAs could participate in the regulation of the inflammatory process and tissue repair in APL/ARDS (Table 1). The levels of miR-16 are lower in experimental APL induced by lipopolysaccharides (LPS). ${ }^{66}$ At the same time, treatment with miR-16 reduces the expression of the proinflammatory cytokines interleukin 6 (IL-6) and tumor necrosis factor a (TNF-a) in macrophages after the exposure to LPS. Recently, Xie et al. also reported a decrease in the pulmonary expression of miR-127 in an animal model of non-infectious APL and in alveolar macrophages exposed to LPS. ${ }^{67}$ Treatment with miR-127 not only reduced the production of IL-1 $\beta$, IL- 6 and TNF- $\alpha$ in macrophages exposed to LPS, but in vivo it also reduced the degree of lesion in the experimental APL. The control of miR-127 on lung inflammation would be mediated through the repression of the CD64 receptor of the macrophages.

Once the lesion is established, repairing the alveolar epithelium is crucial for the recuperation of patients with APL/ARDS. This process requires the proliferation and migration of the epithelial cells. Many patients with APL/ARDS develop hypercapnia due to the compromise of the pulmonary gas exchange, or of the respirator strategy used in case of requiring mechanical ventilation assistance (permissive hypercapnia). Recent evidence suggests that the elevation of the partial $\mathrm{CO}_{2}$ pressure has deleterious effects on the lungs, regardless of the effects on $\mathrm{pH} .{ }^{68}$ Hypercapnia determines an increase of miR-183, causing mitochondrial dysfunction by reducing the expression of the isocitrate dehydrogenase- 2 enzyme (IDH2) ${ }^{69}$ The induction of miR-183 by hypercapnia reduces the proliferation of lung fibroblasts and alveolar epithelial cells. ${ }^{69}$ The reparation of the alveolar epithelium in vitro is affected by hypercapnia as well as by miR-183, although the two factors have not been studied together. ${ }^{70,71}$

\section{Asthma}

Asthma is an inflammatory disease of the airway, characterized by an abnormal response of the Th2-type CD4+T lymphocytes against certain antigens. ${ }^{72}$ In different experimental asthma models, there is an observed increase in the lung expression of miR-21. ${ }^{73}$ This would contribute to the inflammatory process in the airway by means of the repression of IL-12, favoring the Th-2-type lymphocyte response. The levels of miR-126 are also high in experimental asthma and its inhibition represses the activation of Th2 lymphocytes, preventing the development of airway hypersensitivity. ${ }^{74}$ As for the smooth muscle cells, the reduction of miR-133a seems to increase bronchial hyperactivity in an animal model of asthma by increasing the expression of RhoA. ${ }^{75}$ Nevertheless, despite the evidence from experimental models, Williams et al. did not find differences in miRNA expression in airway biopsies between healthy subjects and those with mild asthma. ${ }^{76} \mathrm{New}$ studies will be necessary in order to better comprehend the roles of miRNAs in the pathogenesis of asthma.

\section{Conclusions}

Although the relationship of various miRNAs with lung diseases has been extensively demonstrated, there is still much to understand about the role that each miR plays in their pathogenesis (Table 1). The rhythm at which our understanding of miRNAs is growing leads one to speculate that the knowledge acquired about miRNAs may be transferred to clinical 
practice, where powerful diagnostic and therapeutic tools could be developed. Nevertheless, the complexity of the control system in which they are immersed and the impact that the modification of an miR may have over dozens of mRNA make its pharmacological modulation very challenging.

\section{Acknowledgments}

The authors would like to thank Dr. Markus Queisser for his valuable comments and suggestions.

Funding

This study was financed in part by the US National Institutes of Health (Grants HL-85534 and HL-48129).

\section{References}

1. Nana-Sinkam SP, Hunter MG, Nuovo GJ, Schmittgen TD, Gelinas R, Galas D, et al. Integrating the MicroRNome into the study of lung disease. Am J Respir Crit Care Med. 2009; 179:4-10. [PubMed: 18787215]

2. Tomankova T, Petrek M, Kriegova E. Involvement of microRNAs in physiological and pathological processes in the lung. Respir Res. 2010; 11:159. [PubMed: 21092244]

3. Zhou T, Garcia JG, Zhang W. Integrating microRNAs into a system biology approach to acute lung injury. Transl Res. 2011; 157:180-90. [PubMed: 21420028]

4. Oglesby IK, McElvaney NG, Greene CM. MicroRNAs in inflammatory lung disease-master regulators or target practice? Respir Res. 2010; 11:148. [PubMed: 21029443]

5. Sayed D, Abdellatif M. MicroRNAs in development and disease. Physiol Rev. 2011; 91:827-87. [PubMed: 21742789]

6. Pagdin T, Lavender P. MicroRNAs in lung diseases. Thorax. 2012; 67:183-4. [PubMed: 21836155]

7. Bartel DP. MicroRNAs: genomics, biogenesis, mechanism, and function. Cell. 2004; 116:281-97. [PubMed: 14744438]

8. Lee RC, Feinbaum RL, Ambros V. The C. elegans heterochronic gene lin-4 encodes small RNAs with antisense complementarity to lin-14. Cell. 1993; 75:843-54. [PubMed: 8252621]

9. Kozomara A, Griffiths-Jones S. miRBase: integrating microRNA annotation and deep-sequencing data. Nucleic Acids Res. 2011; 39:D152-7. [PubMed: 21037258]

10. Ender C, Meister G. Argonaute proteins at a glance. J Cell Sci. 2010; 123:1819-23. [PubMed: 20484662]

11. Filipowicz W, Bhattacharyya SN, Sonenberg N. Mechanisms of posttranscriptional regulation by microRNAs: are the answers in sight? Nat Rev Genet. 2008; 9:102-14. [PubMed: 18197166]

12. Guo H, Ingolia NT, Weissman JS, Bartel DP. Mammalian microRNAs predominantly act to decrease target mRNA levels. Nature. 2010; 466:835-40. [PubMed: 20703300]

13. Valadi H, Ekstrom K, Bossios A, Sjostrand M, Lee JJ, Lotvall JO. Exosome-mediated transfer of mRNAs and microRNAs is a novel mechanism of genetic exchange between cells. Nat Cell Biol. 2007; 9:654-9. [PubMed: 17486113]

14. Hergenreider E, Heydt S, Treguer K, Boettger T, Horrevoets AJ, Zeiher AM, et al. Atheroprotective communication between endothelial cells and smooth muscle cells through miRNAs. Nat Cell Biol. 2012; 14:249-56. [PubMed: 22327366]

15. Chen X, Liang H, Zhang J, Zen K, Zhang CY. Secreted microRNAs: a new form of intercellular communication. Trends Cell Biol. 2012; 22:125-32. [PubMed: 22260888]

16. Davis-Dusenbery BN, Hata A. Mechanisms of control of microRNA biogenesis. J Biochem. 2010; 148:381-92. [PubMed: 20833630]

17. Krol J, Loedige I, Filipowicz W. The widespread regulation of microRNA biogenesis, function and decay. Nat Rev Genet. 2010; 11:597-610. [PubMed: 20661255]

18. Salmena L, Poliseno L, Tay Y, Kats L, Pandolfi PP. A ceRNA hypothesis: the Rosetta Stone of a hidden RNA language? Cell. 2011; 146:353-8. [PubMed: 21802130] 
19. Karreth FA, Tay Y, Perna D, Ala U, Tan SM, Rust AG, et al. In vivo identification of tumorsuppressive PTEN ceRNAs in an oncogenic BRAF-induced mouse model of melanoma. Cell. 2011; 147:382-95. [PubMed: 22000016]

20. World Health Organization. World Health Organization fact sheets. 2006. The facts about smoking and health.

21. Gower AC, Steiling K, Brothers JF 2nd, Lenburg ME, Spira A. Transcriptomic studies of the airway field of injury associated with smoking-related lung disease. Proc Am Thorac Soc. 2011; 8:173-9. [PubMed: 21543797]

22. Izzotti A, Calin GA, Arrigo P, Steele VE, Croce CM, De Flora S. Downregulation of microRNA expression in the lungs of rats exposed to cigarette smoke. FASEB J. 2009; 23:806-12. [PubMed: 18952709]

23. Schembri F, Sridhar S, Perdomo C, Gustafson AM, Zhang X, Ergun A, et al. MicroRNAs as modulators of smoking-induced gene expression changes in human airway epithelium. Proc Natl Acad Sci U S A. 2009; 106:2319-24. [PubMed: 19168627]

24. Davidson MR, Larsen JE, Yang IA, Hayward NK, Clarke BE, Duhig EE, et al. MicroRNA-218 is deleted and downregulated in lung squamous cell carcinoma. PLoS One. 2010; 5:e12560. [PubMed: 20838434]

25. Yanaihara N, Caplen N, Bowman E, Seike M, Kumamoto K, Yi M, et al. Unique microRNA molecular profiles in lung cancer diagnosis and prognosis. Cancer Cell. 2006; 9:189-98. [PubMed: 16530703]

26. Van Pottelberge GR, Mestdagh P, Bracke KR, Thas O, Durme YM, Joos GF, et al. MicroRNA expression in induced sputum of smokers and patients with chronic obstructive pulmonary disease. Am J Respir Crit Care Med. 2011; 183:898-906. [PubMed: 21037022]

27. Soriano JB, Rodriguez-Roisin R. Chronic obstructive pulmonary disease overview: epidemiology, risk factors, and clinical presentation. Proc Am Thorac Soc. 2011; 8:363-7. [PubMed: 21816993]

28. Sato T, Liu X, Nelson A, Nakanishi M, Kanaji N, Wang X, et al. Reduced miR-146a increases prostaglandin Ein chronic obstructive pulmonary disease fibroblasts. Am J Respir Crit Care Med. 2010; 182:1020-9. [PubMed: 20522791]

29. Koshiol J, Rotunno M, Consonni D, Pesatori AC, De Matteis S, Goldstein AM, et al. Chronic obstructive pulmonary disease and altered risk of lung cancer in a population-based case-control study. PLoS One. 2009; 4:e7380. [PubMed: 19812684]

30. Ezzie ME, Crawford M, Cho JH, Orellana R, Zhang S, Gelinas R, et al. Gene expression networks in COPD: microRNA and mRNA regulation. Thorax. 2012; 67:122-31. [PubMed: 21940491]

31. Maltais F, LeBlanc P, Whittom F, Simard C, Marquis K, Belanger M, et al. Oxidative enzyme activities of the vastus lateralis muscle and the functional status in patients with COPD. Thorax. 2000; 55:848-53. [PubMed: 10992537]

32. Swallow EB, Reyes D, Hopkinson NS, Man WD, Porcher R, Cetti EJ, et al. Quadriceps strength predicts mortality in patients with moderate to severe chronic obstructive pulmonary disease. Thorax. 2007; 62:115-20. [PubMed: 17090575]

33. Fermoselle C, Rabinovich R, Ausin P, Puig-Vilanova E, Coronell C, Sanchez F, et al. Does oxidative stress modulate limb muscle atrophy in severe copd patients? Eur Respir J. 2012 in press.

34. Lewis A, Riddoch-Contreras J, Natanek SA, Donaldson A, Man WD, Moxham J, et al. Downregulation of the serum response factor/miR-1 axis in the quadriceps of patients with COPD. Thorax. 2012; 67:26-34. [PubMed: 21998125]

35. Jemal A, Siegel R, Ward E, Hao Y, Xu J, Thun MJ. Cancer statistics, 2009. CA Cancer J Clin. 2009; 59:225-49. [PubMed: 19474385]

36. Miller YE. Pathogenesis of lung cancer: 100 year report. Am J Respir Cell Mol Biol. 2005; 33:216-23. [PubMed: 16107574]

37. Lin PY, Yu SL, Yang PC. MicroRNA in lung cancer. Br J Cancer. 2010; 103:1144-8. [PubMed: 20859290]

38. Liu X, Sempere LF, Guo Y, Korc M, Kauppinen S, Freemantle SJ, et al. Involvement of microRNAs in lung cancer biology and therapy. Transl Res. 2011; 157:200-8. [PubMed: 21420030] 
39. Karube Y, Tanaka H, Osada H, Tomida S, Tatematsu Y, Yanagisawa K, et al. Reduced expression of Dicer associated with poor prognosis in lung cancer patients. Cancer Sci. 2005; 96:111-5. [PubMed: 15723655]

40. Hayashita Y, Osada H, Tatematsu Y, Yamada H, Yanagisawa K, Tomida S, et al. A polycistronic microRNA cluster, miR-17-92, is overexpressed in human lung cancers and enhances cell proliferation. Cancer Res. 2005; 65:9628-32. [PubMed: 16266980]

41. Liu X, Sempere LF, Ouyang H, Memoli VA, Andrew AS, Luo Y, et al. MicroRNA-31 functions as an oncogenic microRNA in mouse and human lung cancer cells by repressing specific tumor suppressors. J Clin Invest. 2010; 120:1298-309. [PubMed: 20237410]

42. Seike M, Goto A, Okano T, Bowman ED, Schetter AJ, Horikawa I, et al. MiR-21 is an EGFRregulated anti-apoptotic factor in lung cancer in never-smokers. Proc Natl Acad Sci U S A. 2009; 106:12085-90. [PubMed: 19597153]

43. Takamizawa J, Konishi H, Yanagisawa K, Tomida S, Osada H, Endoh H, et al. Reduced expression of the let-7 microRNAs in human lung cancers in association with shortened postoperative survival. Cancer Res. 2004; 64:3753-6. [PubMed: 15172979]

44. He L, He X, Lim LP, de Stanchina E, Xuan Z, Liang Y, et al. A microRNA component of the p53 tumour suppressor network. Nature. 2007; 447:1130-4. [PubMed: 17554337]

45. Liu X, Sempere LF, Galimberti F, Freemantle SJ, Black C, Dragnev KH, et al. Uncovering growthsuppressive MicroRNAs in lung cancer. Clin Cancer Res. 2009; 15:1177-83. [PubMed: 19228723]

46. Gallardo E, Navarro A, Vinolas N, Marrades RM, Diaz T, Gel B, et al. miR-34a as a prognostic marker of relapse in surgically resected non-small-cell lung cancer. Carcinogenesis. 2009; 30:1903-9. [PubMed: 19736307]

47. Nasser MW, Datta J, Nuovo G, Kutay H, Motiwala T, Majumder S, et al. Downregulation of micro-RNA-1 (miR-1) in lung cancer. Suppression of tumorigenic property of lung cancer cells and their sensitization to doxorubicin-induced apoptosis by miR-1. J Biol Chem. 2008; 283:33394-405. [PubMed: 18818206]

48. Crawford M, Batte K, Yu L, Wu X, Nuovo GJ, Marsh CB, et al. MicroRNA 133B targets prosurvival molecules MCL-1 and BCL2L2 in lung cancer. Biochem Biophys Res Commun. 2009; 388:483-9. [PubMed: 19654003]

49. Skrzypski M, Dziadziuszko R, Jassem J. MicroRNA in lung cancer diagnostics and treatment. Mutat Res. 2011; 717:25-31. [PubMed: 21540042]

50. Yu L, Todd NW, Xing L, Xie Y, Zhang H, Liu Z, et al. Early detection of lung adenocarcinoma in sputum by a panel of microRNA markers. Int J Cancer. 2010; 127:2870-8. [PubMed: 21351266]

51. Xing L, Todd NW, Yu L, Fang H, Jiang F. Early detection of squamous cell lung cancer in sputum by a panel of microRNA markers. Mod Pathol. 2010; 23:1157-64. [PubMed: 20526284]

52. Lodes MJ, Caraballo M, Suciu D, Munro S, Kumar A, Anderson B. Detection of cancer with serum miRNAs on an oligonucleotide microarray. PLoS One. 2009; 4:e6229. [PubMed: 19597549]

53. Yu SL, Chen HY, Chang GC, Chen CY, Chen HW, Singh S, et al. MicroRNA signature predicts survival and relapse in lung cancer. Cancer Cell. 2008; 13:48-57. [PubMed: 18167339]

54. Raponi M, Dossey L, Jatkoe T, Wu X, Chen G, Fan H, et al. MicroRNA classifiers for predicting prognosis of squamous cell lung cancer. Cancer Res. 2009; 69:5776-83. [PubMed: 19584273]

55. Hu Z, Chen X, Zhao Y, Tian T, Jin G, Shu Y, et al. Serum microRNA signatures identified in a genome-wide serum microRNA expression profiling predict survival of non-small-cell lung cancer. J Clin Oncol. 2010; 28:1721-6. [PubMed: 20194856]

56. Raghu G, Collard HR, Egan JJ, Martinez FJ, Behr J, Brown KK, et al. An official ATS/ERS/JRS/ ALAT statement: idiopathic pulmonary fibrosis: evidence-based guidelines for diagnosis and management. Am J Respir Crit Care Med. 2011; 183:788-824. [PubMed: 21471066]

57. King TE Jr, Pardo A, Selman M. Idiopathic pulmonary fibrosis. Lancet. 2011; 378:1949-61. [PubMed: 21719092]

58. Pandit KV, Corcoran D, Yousef H, Yarlagadda M, Tzouvelekis A, Gibson KF, et al. Inhibition and role of let-7d in idiopathic pulmonary fibrosis. Am J Respir Crit Care Med. 2010; 182:220-9.

[PubMed: 20395557] 
59. Willis BC, Borok Z. TGF-beta-induced EMT: mechanisms and implications for fibrotic lung disease. Am J Physiol Lung Cell Mol Physiol. 2007; 293:L525-34. [PubMed: 17631612]

60. Liu G, Friggeri A, Yang Y, Milosevic J, Ding Q, Thannickal VJ, et al. miR-21 mediates fibrogenic activation of pulmonary fibroblasts and lung fibrosis. J Exp Med. 2010; 207:1589-97. [PubMed: 20643828]

61. Yang S, Banerjee S, de Freitas A, Sanders YY, Ding Q, Matalon S, et al. Participation of miR-200 in pulmonary fibrosis. Am J Pathol. 2012; 180:484-93. [PubMed: 22189082]

62. Cushing L, Kuang PP, Qian J, Shao F, Wu J, Little F, et al. miR-29 is a major regulator of genes associated with pulmonary fibrosis. Am J Respir Cell Mol Biol. 2011; 45:287-94. [PubMed: 20971881]

63. Pandit KV, Milosevic J, Kaminski N. MicroRNAs in idiopathic pulmonary fibrosis. Transl Res. 2011; 157:191-9. [PubMed: 21420029]

64. Pottier N, Maurin T, Chevalier B, Puissegur MP, Lebrigand K, Robbe-Sermesant K, et al. Identification of keratinocyte growth factor as a target of microRNA-155 in lung fibroblasts: implication in epithelial-mesenchymal interactions. PLoS One. 2009; 4:e6718. [PubMed: 19701459]

65. Wheeler AP, Bernard GR. Acute lung injury and the acute respiratory distress syndrome: a clinical review. Lancet. 2007; 369:1553-64. [PubMed: 17482987]

66. Cai ZG, Zhang SM, Zhang Y, Zhou YY, Wu HB, Xu XP. MicroRNAs are dynamically regulated and play an important role in LPS-induced lung injury. Can J Physiol Pharmacol. 2012; 90:37-43. [PubMed: 22185353]

67. Xie T, Liang J, Liu N, Wang Q, Li Y, Noble PW, et al. MicroRNA-127 inhibits lung inflammation by targeting IgG Fcgamma receptor I. J Immunol. 2012; 188:2437-44. [PubMed: 22287715]

68. Vadasz I, Hubmayr RD, Nin N, Sporn PH, Sznajder JI. Hypercapnia-a non-permissive environment for the lung. Am J Respir Cell Mol Biol. 2012; 46:417-21. [PubMed: 22246860]

69. Vohwinkel CU, Lecuona E, Sun H, Sommer N, Vadasz I, Chandel NS, et al. Elevated CO(2) levels cause mitochondrial dysfunction and impair cell proliferation. J Biol Chem. 2011; 286:37067-76. [PubMed: 21903582]

70. O’Toole D, Hassett P, Contreras M, Higgins BD, McKeown ST, McAuley DF, et al. Hypercapnic acidosis attenuates pulmonary epithelial wound repair by an NF-kappaB dependent mechanism. Thorax. 2009; 64:976-82. [PubMed: 19617214]

71. Wang G, Mao W, Zheng S. MicroRNA-183 regulates Ezrin expression in lung cancer cells. FEBS Lett. 2008; 582:3663-8. [PubMed: 18840437]

72. Locksley RM. Asthma and allergic inflammation. Cell. 2010; 140:777-83. [PubMed: 20303868]

73. Lu TX, Munitz A, Rothenberg ME. MicroRNA-21 is up-regulated in allergic airway inflammation and regulates IL-12p35 expression. J Immunol. 2009; 182:4994-5002. [PubMed: 19342679]

74. Mattes J, Collison A, Plank M, Phipps S, Foster PS. Antagonism of microRNA-126 suppresses the effector function of TH2 cells and the development of allergic airways disease. Proc Natl Acad Sci U S A. 2009; 106:18704-9. [PubMed: 19843690]

75. Chiba Y, Misawa M. MicroRNAs and their therapeutic potential for human diseases: MiR-133a and bronchial smooth muscle hyperresponsiveness in asthma. J Pharmacol Sci. 2010; 114:264-8. [PubMed: 20953121]

76. Williams AE, Larner-Svensson H, Perry MM, Campbell GA, Herrick SE, Adcock IM, et al. MicroRNA expression profiling in mild asthmatic human airways and effect of corticosteroid therapy. PLoS One. 2009; 4:e5889. [PubMed: 19521514] 


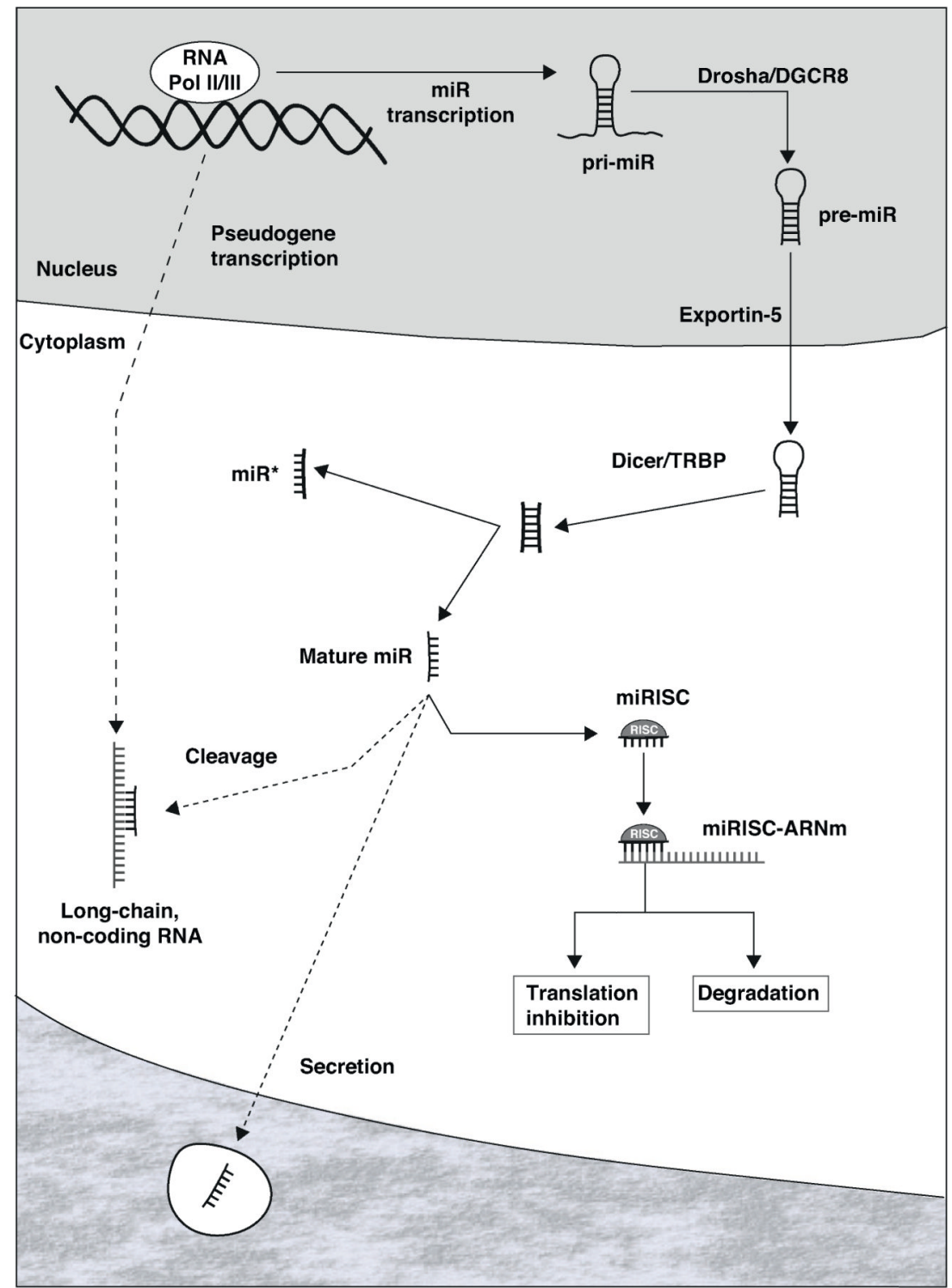

Fig. 1.

Schematic representation of the different stages in the biogenesis of miRs and repression mechanisms of gene expression: mRNA degradation or inhibition of its translation. Also shown are the possible secretions of miRs, as well as their interaction with non-coding, long-chain RNA. 
Table 1

MicroRNAs in Lung Diseases.

\begin{tabular}{lll}
\hline let-7 & Cancer, COPD, smoking & Reduced $^{22,25,26,43,53,58}$ \\
miR-1 & COPD, cancer & Reduced $^{34,47}$ \\
miR-10a & Smoking & Reduced $^{22}$ \\
miR-15/107 & COPD & Increased $^{30}$ \\
miR-16 & Lung lesion & Reduced $^{66}$ \\
miR-17-92 group & Cancer & Increased $^{40}$ \\
miR-21 & Cancer, fibrosis, asthma & Increased $^{42,60,73}$ \\
miR-29 & Fibrosis & Reduced $^{58,62,63}$ \\
miR-31 & Cancer & Increased $^{41}$ \\
miR-34 & Cancer, smoking & Reduced $^{22,26,45,46}$ \\
miR-123 & Smoking & Reduced $^{22}$ \\
miR-126 & Asthma & Increased $^{74}$ \\
miR-127 & Lung lesion & Reduced $^{67}$ \\
miR-133a & Asthma & Reduced $^{75}$ \\
miR-133b & Cancer & Reduced $^{48}$ \\
miR-145 & Smoking & Reduced $^{22}$ \\
miR-146a & COPD & Reduced $^{26,28}$ \\
miR-146b & Cancer & Increased $^{54}$ \\
miR-150 & Smoking, COPD & Reduced $^{26}$ \\
miR-155 & Cancer, fibrosis & Increased $^{25,58,64}$ \\
miR-183 & Hypercapnia & Increased $^{69}$ \\
miR-199b & Smoking & Reduced $^{23,25}$ \\
miR-200 & Fibrosis & Reduced $^{61}$ \\
miR-218 & Cancer, smoking & Reduced $^{23,24}$ \\
miR-222 & Smoking & Reduced $^{22,26}$ \\
\hline & & \\
\hline mD & &
\end{tabular}

COPD: chronic obstructive pulmonary disease. 